\title{
Stroke Patterns and Cannulation Strategy during Veno-Arterial Extracorporeal Membrane Support
}

\author{
Mia Nishikawa ${ }^{1}$, Joshua Willey ${ }^{1}$, Hiroo Takayama ${ }^{1}$, Yuji Kaku ${ }^{1}$, Yuming Ning ${ }^{1}$, Paul \\ Kurlansky $^{1}$, Daniel Brodie ${ }^{1}$, Amir Masoumi ${ }^{2}$, Justin Fried ${ }^{1}$, and Koji Takeda ${ }^{1}$ \\ ${ }^{1}$ Columbia University Irving Medical Center \\ ${ }^{2}$ Columbia University Medical Center
}

October 27, 2020

\begin{abstract}
Objectives Stroke has potentially devastating consequences for patients receiving veno-arterial extracorporeal membrane support (VA-ECMO). Arterial cannulation sites for VA-ECMO include the ascending aorta, axillary artery, and femoral artery. However, the influence of cannulation site on stroke risk has not been well described. The purpose of this study was to investigate the association between occurrence and patterns of stroke with ECMO arterial cannulation sites. Methods We retrospectively reviewed 414 consecutive patients who received VA-ECMO support for cardiogenic shock between March 2007 and May 2018. Patients were categorized by cannulation strategy. The rates, subtype and location of strokes as assessed by neuroimaging during and after VA-ECMO support were analyzed. Results Median age was 61 years (IQR 50-69); 67\% were men. 77 patients were cannulated via the ascending aorta (17\%), 31 via the axillary artery (7\%), and $306(69 \%)$ via the femoral artery. In total, 26 patients $(6.3 \%)$ developed 30 stroke lesions at a median of 6.0 (IQR 3.1-8.7) days after ECMO cannulation. Ischemic stroke was the most common subtype (64\%), followed by hemorrhagic transformation (20\%) and hemorrhagic stroke (16\%). Location by CT was right hemispheric in $38 \%$, left hemispheric in $24 \%$, bilateral in $21 \%$, and vertebrobasilar in $17 \%$. The incidence of stroke was similar across cannulation strategies: aorta $(\mathrm{n}=5,6.5 \%)$, axillary artery $(\mathrm{n}=2,6.5 \%)$, and femoral artery ( $\mathrm{n}=19$, $6.2 \%),(\mathrm{p}=0.99)$. Conclusions Incidence of stroke does not appear to differ among patients cannulated via the ascending aorta, axillary artery, or femoral artery. Ischemic stroke was the most common subtype of stroke.
\end{abstract}

Title page

Stroke Patterns and Cannulation Strategy during Veno-Arterial Extracorporeal Membrane Support

Running head: Stroke and VA-ECMO cannulation strategy

Mia Nishikawa, $\mathrm{BA}^{1}$, Joshua Willey, $\mathrm{MD}^{2}$, Hiroo Takayama, $\mathrm{MD}, \mathrm{PhD}^{1}$, Yuji Kaku, $\mathrm{MD}^{1}$, Yuming Ning, $\mathrm{PhD}^{3}$, Paul A. Kurlansky, $\mathrm{MD}^{1}$, Daniel Brodie, $\mathrm{MD}^{4}$, Amirali Masoumi, MD ${ }^{5}$, Justin Fried, MD ${ }^{5}$, Koji Takeda, MD, $\mathrm{PhD}^{1}$

Total word count: 4332

Brief title: Stroke and ECMO Arterial Cannulation Strategy

${ }^{1}$ Department of Surgery, Division of Cardiothoracic Surgery

${ }^{2}$ Department of Neurology

${ }^{3}$ Department of Surgery, Center for Innovation and Outcomes Research

${ }^{4}$ Department of Medicine, Division of Pulmonary and Critical Care Medicine 
${ }^{5}$ Department of Medicine, Division of Cardiology

Columbia University Medical Center, New York, NY

Address for correspondence:

Dr. Koji Takeda

177 Fort Washington Avenue, New York, NY 10032

Telephone: 212-305-6380; Fax: 212-342-3520 E-mail: kt2485@cumc.columbia.edu

\section{Data availability statement:}

The authors confirm that the data supporting the findings of this study are available within the article and/or its supplementary materials.

\section{Funding Statement:}

The authors received no specific funding for this work.

\section{Conflicts of Interest:}

Daniel Brodie receives research support from ALung Technologies and he was previously on their medical advisory board. He has been on the medical advisory boards for Baxter, BREETHE, Xenios, and Hemovent. The remaining authors have no conflicts of interest to disclose.

\section{Institutional Review Board:}

This study was approved by the institutional review board of the Columbia University Irving Medical Center.

\section{Abstract \\ Objectives}

Stroke has potentially devastating consequences for patients receiving veno-arterial extracorporeal membrane support (VA-ECMO). Arterial cannulation sites for VA-ECMO include the ascending aorta, axillary artery, and femoral artery. However, the influence of cannulation site on stroke risk has not been well described. The purpose of this study was to investigate the association between occurrence and patterns of stroke with ECMO arterial cannulation sites.

\section{Methods}

We retrospectively reviewed 414 consecutive patients who received VA-ECMO support for cardiogenic shock between March 2007 and May 2018. Patients were categorized by cannulation strategy. The rates, subtype and location of strokes as assessed by neuroimaging during and after VA-ECMO support were analyzed.

Results

Median age was 61 years (IQR 50-69); $67 \%$ were men. 77 patients were cannulated via the ascending aorta (17\%), 31 via the axillary artery (7\%), and $306(69 \%)$ via the femoral artery. In total, 26 patients (6.3\%) developed 30 stroke lesions at a median of 6.0 (IQR 3.1-8.7) days after ECMO cannulation. Ischemic stroke was the most common subtype (64\%), followed by hemorrhagic transformation (20\%) and hemorrhagic stroke (16\%). Location by CT was right hemispheric in $38 \%$, left hemispheric in $24 \%$, bilateral in $21 \%$, and vertebrobasilar in 17\%. The incidence of stroke was similar across cannulation strategies: aorta $(\mathrm{n}=5,6.5 \%)$, axillary artery $(\mathrm{n}=2,6.5 \%)$, and femoral artery $(\mathrm{n}=19,6.2 \%),(\mathrm{p}=0.99)$.

\section{Conclusions}

Incidence of stroke does not appear to differ among patients cannulated via the ascending aorta, axillary artery, or femoral artery. Ischemic stroke was the most common subtype of stroke. 
Word Count: 248

Key words : stroke, cerebrovascular accident, extracorporeal membrane support, ECMO

Introduction

Veno-arterial extracorporeal membrane support (VA-ECMO) utilization for cardiogenic shock has markedly increased in the past few decades, as technological advances have resulted in equipment improvement and expanded indications ${ }^{1-4}$. Etiologies of cardiogenic shock include, but are not limited to, postcardiotomy shock, acute myocardial infarction, allogenic graft dysfunction, and acute decompensated heart failure. Despite successful outcomes in VA-ECMO deployment, complications are common and mortality rates remain high $^{5}$.

Stroke is a major complication with potentially devastating consequences, including mortality and long-term disability. Reported stroke incidence during VA-ECMO have ranged from $4.2-8 \%$ and stroke remains a leading cause of mortality for patients on $\mathrm{VA}-\mathrm{ECMO}^{6-8}$. The pathophysiology of stroke during ECMO is complex and suggested to be influenced by several factors, including cerebral autoregulation, anticoagulation, vasospasm, circuit thrombosis, and thromboembolism, however specific mechanisms are poorly understood. ${ }^{9}$

Arterial cannulation sites for VA-ECMO include ascending aorta, axillary artery, and femoral artery. There is scarce data about the rates of stroke according to cannulation site. In older case series of VA-ECMO, high rates were explained by ligation or cannulation of the internal carotid, however more contemporary studies continue to document high rates of stroke despite alternative cannulation sites. The purpose of this study was to investigate the association between occurrence and patterns of stroke with ECMO arterial cannulation sites. We hypothesize that stroke risk would vary with arterial cannulation site.

\section{Methods}

\section{Study Population}

All patients $(\mathrm{n}=414)$ who received VA-ECMO support for cardiogenic shock at our center between March 22, 2007 and June 26, 2018 were identified through our clinical outcomes database. This study was approved by the institutional review board of the Columbia University Irving Medical Center.

\section{Cannulation Strategy and ECMO management}

Our ECMO strategy and management is described previously ${ }^{10}$. The Cardiohelp system (Maquet, Wayne, NJ) was the primary circuit used in our institution but CentriMag or Rotaflow pump was rarely used. In brief, femoral vessel cannulation was usually preferred for all cardiogenic shock patients throughout the study period, however central cannulation was typically used for post-cardiotomy circumstances or when peripheral arterial sites were inaccessible, and axillary cannulation used when femoral arteries were inaccessible or when the axillary artery is cut-down for other purposes. ECMO was managed by multidisciplinary team. Patients were classified based on initial arterial cannulation site.

\section{Stroke definition, diagnosis, and classification}

In line with the most recently updated definitions by the American Heart Association ${ }^{11}$, ischemic stroke (IS) was defined as any focal neurological deficit either with an associated infarct noted on neuro-imaging or with clinical evidence of cerebral focal ischemic injury lasting at least 24 hours. Intracerebral hemorrhage (ICH) was defined as intra-parenchymal bleeding not related to trauma without evidence of significant adjacent hypodensity on computed tomography (CT) scan. Ischemic Stroke with hemorrhagic transformation (HT) was defined as intra-parenchymal bleeding with significant adjacent hypodensity on CT, consistent with hemorrhage into the bed of an infarct.

Patient sedation was turned off on a daily basis for neurological monitoring, and patients with suspected stroke were examined by a board-certified neurologist at our institution and underwent a full neurological examination. We defined strokes occurring within 7 days of ECMO decannulation as ECMO-related stroke because, in some cases, clinical neurological examinations were not feasible or reliable due to delirium or 
other causes and diagnosis of stroke could be delayed ${ }^{7}$. Anticoagulation was held until neurological evaluation was completed. Condition permitting, patients underwent neuro-imaging with non-contrast computed tomography (CT). Patients with negative findings on CT but with clinical suspicion of stroke underwent further neuroimaging, with two patients with confirmed stroke on computed tomography angiography, and one patient with confirmed stroke on magnetic resonance imaging. Stroke lesions were confirmed with neuroimaging findings and classified as IS, HT or ICH and were subdivided into right hemispheric, left hemispheric, bilateral hemispheric, or vertebrobasilar lesions. One patient with clinically apparent stroke had their care withdrawn before undergoing neuroimaging. This patient, although classified as having a stroke event, was not included in the stroke subtype and location analysis due to the absence of neuroimaging. Ischemic stroke lesions that underwent hemorrhagic transformation were classified as one stroke event. In 3 patients, stroke became evident after ECMO decannulation. For patients who were decannulated from ECMO and had a stroke event after being transferred to a separate mechanical circulatory device, determining whether the stroke was related to ECMO or another device is difficult. As such, patients with stroke event occurring 7 days post-ECMO removal or occurring within 7 days post-ECMO removal while being supported on a separate mechanical circulatory device (except for an Impella device or intra-aortic balloon pump ("IABP")) were classified as having no stroke event, as these stroke events were not considered to have occurred while on ECMO.

\section{Data Collection}

Data was collected from either a preexisting database of adult ECMO patients, where available, or directly from patient charts. Baseline demographic information, including age, gender, body mass index, comorbidities, and etiology of cardiogenic shock was recorded for all patients. Characteristics of ECMO support in each patient were also collected. Each head CT imaging was reviewed by a single board certified vascular neurologist (JW) to determine the type and location of stroke.

\section{Statistical Analysis}

Continuous variables were represented as median (interquartile range [IQR]) and compared using the MannWhitney test (for two way comparisons) or Kruskal-Wallis test (for three way comparisons) as they were not normally distributed by testing with the Kolmogorov-Smirnov test. Categorical variables were represented as proportions and compared using chi-square and Fisher's exact tests where appropriate. P-value less than 0.05 was considered significant for all analyses. When Kruskal-Wallis test or chi-square tests showed significance, post-hoc comparisons with Bonferroni correction were further performed to examine the significant differences pairwise. Chi-square tests were used to evaluate differences between those with and without stroke. All statistical analyses were performed using IBM SPSS software version 26.0 (IBM, Armonk, NY, USA).

\section{Results}

\section{Baseline Characteristics}

Table S1 shows baseline characteristics (see Supplementary Table S1). Median age of the cohort was 61 years (IQR 50-69); 67\% were men. A total of 30 stroke events occurred in 26 patients $(6.3 \%)$ at a median of 6.0 (3.1-8.7) days after ECMO cannulation. There were no significant differences in baseline demographic characteristics such as age, sex, or body mass index between patients who had stroke and those who did not. Arteriosclerotic risk factors such as hypertension, hyperlipidemia, diabetes mellitus, previous history of stroke, and underlying etiologies of cardiogenic shock were not significantly associated with increased risk for stroke. Rate of concurrent use of other devices such as intra-aortic balloon pump or Impella, baseline lactic acid levels, and active cardiopulmonary resuscitation prior to ECMO cannulation was also similar between the groups.

Among 414 patients in our cohort, 77 patients were cannulated via the ascending aorta (19\%), 31 patients via the axillary artery $(7 \%)$, and $306(74 \%)$ patients via the femoral artery. Table 1 shows patient demographics based on the cannulation type. Baseline characteristics and co-morbidities were not significantly different among groups. 


\section{Stroke type and location}

Stroke subtype and location based on cannulation site are summarized in Table 2. IS was the most common stroke subtype $(64 \%)$, followed by HT $(20 \%)$ and ICH (16\%). Among these, location by CT scan was right hemispheric in $38 \%$, left hemispheric in $24 \%$, bilateral in $21 \%$, and vertebrobasilar in $17 \%$.

Stroke incidence did not appear to differ across cannulation strategies: aorta $(\mathrm{n}=4,6.5 \%)$, axillary artery $(\mathrm{n}=2,6.5 \%)$, and femoral artery $(\mathrm{n}=19,6.2 \%),(\mathrm{p}=0.99)$. Median days to stroke event from ECMO cannulation were 7.0, 1.74, and 6.0 days for ascending aorta, axillary artery, and femoral artery cannulation, respectively. Stroke patients with axillary cannulation had right hemispheric stroke $(\mathrm{n}=1,50 \%)$ and vertebrobasilar stroke $(n=1,50 \%)$. Those with central cannulation had left hemispheric $(n=2,50 \%)$, right hemispheric $(\mathrm{n}=1,25 \%)$, and bilateral lesions $(\mathrm{n}=1,25 \%)$. Those with femoral cannulation had right hemispheric $(\mathrm{n}=9,39 \%)$, left hemispheric $(\mathrm{n}=5,22 \%)$, bilateral $(\mathrm{n}=5,22 \%)$, and vertebrobasilar lesions $(\mathrm{n}=4$, $17 \%)$ lesions.

Among etiologies for cardiogenic shock, the incidences of stroke seen in patients with acute decompensated heart failure, other etiologies for cardiogenic shock, acute myocardial injury, postcardiotomy shock, and graft dysfunction were $9 \%, 8 \%, 7 \%, 7 \%$, and $4 \%$ respectively $(\mathrm{p}=0.13)$.

\section{Outcomes Comparison}

Across cannulation sites, infection rates appeared to be highest in patients with femoral cannulation (31\%) compared to axillary cannulation (29\%), and central cannulation $(18 \%),(\mathrm{p}=0.046) .62 \%$ of the femoral cannulation cohort required distal perfusion cannula for distal ischemia. Bleeding rates were observed to be $52 \%, 58 \%$, and $43 \%$ in patients with central, axillary, and femoral cannulation, respectively $(\mathrm{p}=0.17)$. Overall survival to discharge in this cohort was $51.0 \%$. Survival to discharge rates was $52 \%$ in the stroke-free population compared to $42 \%$ in the stroke population, without reaching statistical significance due to sample size $(\mathrm{p}=0.36)$.

Among stroke patients who survived to discharge, 4 patients (36\%) had resolved neurologic deficit, and 7 patients $(64 \%)$ were previously independent and unable to perform ADLs at the time of discharge (Table 3). Overall survival to discharge for patients who received femoral, axillary, and central cannulation was 37\%, $100 \%, 40 \%$, respectively $(\mathrm{p}=0.22)$.

\section{Discussion}

The major finding of this study is that VA-ECMO cannulation location did not appear associated with stroke risk. Ischemic stroke was the most common stroke subtype, followed by hemorrhagic transformation, and intracranial hemorrhage. Lesions were most common in the right hemisphere, followed by the left hemisphere lesions, bilateral lesions, and vertebrobasilar lesions.

Current literature suggests that $10-50 \%$ of VA-ECMO patients suffer neurological complications ${ }^{6,8,12}$. Variable incidence rates may be attributed to inconsistent definition of what constitutes a neurological complication, with some studies including brain death, diffuse anoxic brain injury, and coma under the scope of neurological complications while other studies do not. Neurological complications include subclinical cognitive impairment, seizures, paraplegia, peripheral neuropathy, and ischemic and hemorrhagic strokes. Ischemic stroke and hemorrhagic stroke are catastrophic complications associated with ECMO. Incidence rates for stroke range from 4.2-7.8\% among VA-ECMO patients ${ }^{6-8}$. The true stroke incidence rate may be higher as stroke events are likely unrecognized. Neurological diagnosis is often difficult due to deep sedation and systolic and metabolic derangements encountered in intensive care unit patients. In a prospective study, Mateen et al. found that despite a lack of clinical diagnosis of stroke, autopsy studies of 9 of 10 brains showed hypoxic-ischemic and hemorrhagic lesions of vascular origin ${ }^{12}$.

The specific pathophysiology leading to ischemic or hemorrhagic stroke during VA-ECMO is poorly understood. There are multiple proposed stroke risk factors in patients undergoing VA-ECMO. Such risk factors may include cardiac arrest, cardiac surgery, myocardial infarction, heart failure, need for renal re- 
placement therapy, sepsis, duration of ECMO, presence of bleeding at other sites, and non-pulsatile cerebral perfusion $^{7,13,14}$. Small studies have suggested that certain risk factors are independently associated with stroke: Omar et al. found that high pre-ECMO blood lactic acid levels (lactic acid $>10 \mathrm{mmol} / \mathrm{L}$ ) were independently associated with ischemic stroke ${ }^{9}$. In a retrospective, single-center study, Saeed et al. found a strong association between early low-level hemolysis (i.e. 48-hour plasma-free hemoglobin 11-50 mg/dL) with subsequent non-hemorrhagic stroke ${ }^{15}$. However, both studies were limited by small number of cases with the main outcome variable. As such, assessing the relative impacts of the underlying risk factor and ECMO itself is challenging.

Cannulation site is a potentially modifiable risk factor that has not been extensively studied. The association between outflow cannulation site and neurological complications has been studied among pediatric VAECMO patients with mixed results. Incidence rate of neurological complications in neonatal VA-ECMO patients has been estimated to be $20 \%^{16}$. A study of pediatric VA-ECMO patients by Werho et al. ${ }^{17}$ did not find association between stroke risk and cannulation site in neonates. Another study by Pinto et al. ${ }^{19}$ found that peripheral cannulation was associated with higher incidence of stroke in pediatric patients. Few studies have studied such associations among adult VA-ECMO patients. Laterality of lesions have not been extensively studied in adult VA-ECMO patients, and reports in pediatric patients have been conflicting ${ }^{19,}{ }^{21}$.

This study is subject to limitations particular to non-randomized studies. Due to the small number of cases with the main outcome variable, a main study limitation is the low statistical power of the analysis. In order for our study to have $80 \%$ power at alpha $=0.05$, the effect size, as demonstrated by the odds ratio, would have to be at least 6 (compared to our findings, where $\mathrm{OR}=1.05$ for both axillary vs. femoral cannulation and central vs. femoral cannulation, and $\mathrm{OR}=1$ for axillary vs. central cannulation). Therefore, our study was underpowered to detect a difference in stroke rates based on cannulation site, if such a difference existed. Second, selection bias may have been introduced in terms of choice of cannulation strategy due to accessibility. For example, most patients who received central cannulation had underlying etiology of postcardiotomy shock for ease of access, and patients with femoral cannulation were more likely to have acute myocardial infarction as underlying cardiogenic shock etiology, as shown by pairwise comparisons with $\mathrm{p}<0.01$ of Bonferroni correction. Larger, multi-center studies are needed to confirm these findings. In order to lower the risk of information bias, all documented stroke outcomes were verified with a CT scan of the head. Therefore, overall incidence of stroke is likely underestimated. Furthermore, the long study period (12 years) introduces technological advances that may have changed patient management during the study period (see Supplementary Table S2).

\section{Conclusion}

In conclusion, ischemic or hemorrhagic stroke rates did not appear to differ across cannulation sites during VA-ECMO.

\section{Funding Statement}

The authors received no specific funding for this work.

\section{Conflicts of Interest:}

Daniel Brodie receives research support from ALung Technologies and he was previously on their medical advisory board. He has been on the medical advisory boards for Baxter, BREETHE, Xenios, and Hemovent. The remaining authors have no conflicts of interest to disclose.

\section{Author Contributions:}

Mia Nishikawa: Conceptualization; Data curation; Formal analysis; Investigation; Methodology; Writingoriginal draft; Writing - review \& editing. Joshua Willey: Investigation; Methodology; Writing — review \& editing. Hiroo Takayama:Writing - review \& editing. Yuji Kaku: Writing - review \& editing. Yuming Ning: Formal analysis; Writing - original draft; Writing - review \& editing. Paul Kurlansky:Writingreview \& editing. Daniel Brodie: Writing - review \& editing. Amirali Masoumi: Writing - review \& 
editing.Justin Fried: Writing - review \& editing. Koji Takeda: Conceptualization; Data curation; Formal analysis; Investigation; Methodology; Writing - original draft; Writing - review \& editing; Supervision.

Tables

Table 1: Demographics and Clinical Characteristics of VA ECMO Patients based on Cannulation Type

\begin{tabular}{|c|c|c|c|c|c|c|c|c|}
\hline & $\begin{array}{l}\text { All } \\
(\mathrm{n}=414)\end{array}$ & $\begin{array}{l}\text { All } \\
(\mathrm{n}=414)\end{array}$ & $\begin{array}{l}\text { Central } \\
(\mathrm{n}=77)\end{array}$ & $\begin{array}{l}\text { Central } \\
(\mathrm{n}=77)\end{array}$ & $\begin{array}{l}\text { Axillary } \\
(\mathrm{n}=31)\end{array}$ & $\begin{array}{l}\text { Axillary } \\
(\mathrm{n}=31)\end{array}$ & $\begin{array}{l}\text { Femoral } \\
(\mathrm{n}=306)\end{array}$ & $\begin{array}{l}\text { Femoral } \\
(\mathrm{n}=306)\end{array}$ \\
\hline \multicolumn{2}{|c|}{ Characteristic } & \multirow{2}{*}{$\begin{array}{l}\%, \text { IQR } \\
(50.0- \\
69.0)\end{array}$} & \multirow[b]{2}{*}{62.0} & \multirow{2}{*}{$\begin{array}{l}\%, \text { IQR } \\
(51.5- \\
72.0)\end{array}$} & \multirow[b]{2}{*}{62.0} & \multirow{2}{*}{$\begin{array}{l}\%, \text { IQR } \\
(51.0- \\
72.0)\end{array}$} & \multirow[b]{2}{*}{61.0} & \multirow{2}{*}{$\begin{array}{l}\%, \text { IQR } \\
(49.8- \\
69.0)\end{array}$} \\
\hline $\begin{array}{l}\text { Age, } \\
\text { median } \\
(\mathrm{IQR}) \\
\text { (years) }\end{array}$ & 61.0 & & & & & & & \\
\hline $\begin{array}{l}\text { BMI, } \\
\text { median } \\
(\mathrm{IQR}) \\
\left(\mathrm{kg} / \mathrm{m}^{2}\right)\end{array}$ & 28.1 & $(24.3-32.2)$ & 28.5 & $(24.2-31.9)$ & 30.0 & $(25.1-32.1)$ & 27.9 & $(24.4-32.3)$ \\
\hline $\begin{array}{l}\text { Male, } \\
\text { n (\%) }\end{array}$ & 276 & $66.7 \%$ & 48 & $62.3 \%$ & 21 & $67.7 \%$ & 207 & $67.7 \%$ \\
\hline $\begin{array}{l}\text { Prior } \\
\text { CVA, n } \\
(\%)\end{array}$ & 36 & $10.9 \%$ & 6 & $9.1 \%$ & 2 & $8.3 \%$ & 28 & $11.6 \%$ \\
\hline $\begin{array}{l}\text { HTN, } \\
\text { n }(\%)\end{array}$ & 208 & $62.7 \%$ & 43 & $65.2 \%$ & 15 & $62.5 \%$ & 150 & $62.0 \%$ \\
\hline $\begin{array}{l}\text { HLD, n } \\
(\%)\end{array}$ & 158 & $47.5 \%$ & 31 & $47.0 \%$ & 9 & $37.5 \%$ & 118 & $48.6 \%$ \\
\hline $\begin{array}{l}\text { DM, n } \\
(\%) \\
\text { Etiology, } \\
\text { n }(\%)\end{array}$ & 108 & $32.4 \%$ & 18 & $27.3 \%$ & 6 & $25.0 \%$ & 84 & $34.6 \%$ \\
\hline $\begin{array}{l}\text { PCS, n } \\
(\%)\end{array}$ & 135 & $32.6 \%$ & 49 & $63.6 \%$ & 20 & $64.5 \%$ & 66 & $24.4 \%$ \\
\hline $\begin{array}{l}\text { Graft, } \\
\mathrm{n}(\%)\end{array}$ & 54 & $13.0 \%$ & 8 & $10.4 \%$ & 1 & $3.2 \%$ & 45 & $16.6 \%$ \\
\hline $\begin{array}{l}\mathrm{ADHF}, \\
\mathrm{n}(\%)\end{array}$ & 44 & $10.6 \%$ & 3 & $3.9 \%$ & 4 & $12.9 \%$ & 37 & $13.7 \%$ \\
\hline $\begin{array}{l}\text { AMI, n } \\
(\%)\end{array}$ & 94 & $22.7 \%$ & 7 & $9.1 \%$ & 5 & $16.1 \%$ & 82 & $30.3 \%$ \\
\hline $\begin{array}{l}\text { Other, } \\
\mathrm{n}(\%)\end{array}$ & 51 & $12.3 \%$ & 9 & $11.7 \%$ & 1 & $3.2 \%$ & 41 & $15.1 \%$ \\
\hline
\end{tabular}

$\mathrm{ADHF}=$ Acute Decompensated Heart Failure; AMI = Acute Myocardial Injury; BMI = Body Mass Index; CVA = Cerebrovascular Accident; DM = Diabetes; Graft = Primary Graft Dysfunction; HLD = Hyperlipidemia; HTN = Hypertension; PCS = Postcardiotomy Shock; PCS includes those patients with inability to wean from cardiopulmonary bypass secondary to left, right or biventricular failure.

Table 2: Stroke Subtype and Location based on Cannulation Site 


\begin{tabular}{|c|c|c|c|c|c|c|c|c|}
\hline & All & & Central & Central & Axillary & Axillary & Femoral & Femoral \\
\hline $\begin{array}{l}\text { Patients } \\
\text { with } \\
\text { Stroke, n } \\
(\%)\end{array}$ & 26 & $\begin{array}{l}26 / 414, \\
6 \%\end{array}$ & 5 & $5 / 77,6 \%$ & 2 & $2 / 31,6 \%$ & 19 & $\begin{array}{l}19 / 306, \\
6 \%\end{array}$ \\
\hline IS & 16 & $\begin{array}{l}16 / 25 \\
64 \%\end{array}$ & 4 & $4 / 4,100 \%$ & 1 & $1 / 2,50 \%$ & 11 & $\begin{array}{l}11 / 19 \\
58 \%\end{array}$ \\
\hline HT & 5 & $5 / 25,20 \%$ & 0 & $0 / 4,0 \%$ & 1 & $1 / 2,50 \%$ & 4 & $4 / 19,21 \%$ \\
\hline $\mathrm{ICH}$ & 4 & $4 / 25,16 \%$ & 0 & $0 / 4,0 \%$ & 0 & $0 / 0,0 \%$ & 4 & $4 / 19,21 \%$ \\
\hline $\begin{array}{l}\text { Stroke } \\
\text { events, n } \\
(\%)\end{array}$ & 30 & & 5 & $5 / 30,17 \%$ & 2 & $2 / 30,7 \%$ & 23 & $\begin{array}{l}23 / 30 \\
77 \%\end{array}$ \\
\hline R Hemi & 11 & $\begin{array}{l}11 / 29 \\
38 \%\end{array}$ & 1 & $1 / 4,25 \%$ & 1 & $1 / 2,50 \%$ & 9 & $9 / 23,39 \%$ \\
\hline L Hemi & 7 & $7 / 29,24 \%$ & 2 & $2 / 4,50 \%$ & 0 & $0 / 2,0 \%$ & 5 & $5 / 23,22 \%$ \\
\hline BL & 6 & $6 / 29,21 \%$ & 1 & $1 / 4,25 \%$ & 0 & $0 / 2,0 \%$ & 5 & $5 / 23,22 \%$ \\
\hline VB & 5 & $5 / 29,17 \%$ & 0 & $0 / 4,0 \%$ & 1 & $1 / 2,50 \%$ & 4 & $4 / 23,17 \%$ \\
\hline
\end{tabular}

$\mathrm{BL}=$ Bilateral Hemispheric Stroke; HT $=$ Hemorrhagic Transformation of an Ischemic Stroke; ICH $=$ Intracranial Hemorrhage; IS = Ischemic Stroke; L Hemi = Left Hemispheric Stroke; R Hemi = Right Hemispheric Stroke; VB = Vertebrobasilar Stroke.

$\backslash$ sout

Table 3: Survival and Functional Outcomes of Stroke Patients based on Cannulation Site

\begin{tabular}{llllllllll}
\hline & All & & Central & Central & Axillary & Axillary & Femoral & Femoral & p-value \\
\hline Survival-to-discharge, n (\%) & 11 & $42 \%$ & 2 & $40 \%$ & 2 & $100 \%$ & 7 & $37 \%$ & 0.22 \\
Resolved neurologic deficit, n (\%) & 4 & $36 \%$ & 1 & $50 \%$ & 0 & $0 \%$ & 3 & $43 \%$ & 0.49 \\
Unable to perform ADLs, n (\%) & 7 & $64 \%$ & 1 & $50 \%$ & 2 & $100 \%$ & 4 & $57 \%$ & 0.49 \\
\hline
\end{tabular}

$\mathrm{ADL}=$ activities of daily living

\section{Supplementary Tables S1-S2}

Supplementary Table S1: Characteristics of Stroke versus Stroke-free VA ECMO Patients

\begin{tabular}{|c|c|c|c|c|c|c|c|}
\hline & All $(\mathrm{n}=414)$ & All $(\mathrm{n}=414)$ & $\begin{array}{l}\text { Non-Stroke } \\
\text { Patients } \\
(\mathrm{n}=388)\end{array}$ & $\begin{array}{l}\text { Non-Stroke } \\
\text { Patients } \\
(\mathrm{n}=388)\end{array}$ & $\begin{array}{l}\text { Stroke } \\
(\mathrm{n}=26)\end{array}$ & $\begin{array}{l}\text { Stroke } \\
(\mathrm{n}=26)\end{array}$ & $\mathrm{P}$-value \\
\hline $\begin{array}{l}\text { Age, } \\
\text { median } \\
\text { (IQR) } \\
\text { (years) }\end{array}$ & 61.0 & $(50.0-69.0)$ & 61.0 & $(50.0-69.0)$ & 60.5 & $(44.0-70.3)$ & 0.56 \\
\hline $\begin{array}{l}\text { BMI, } \\
\text { median } \\
(\mathrm{IQR}) \\
\left(\mathrm{kg} / \mathrm{m}^{2}\right)\end{array}$ & 28.1 & $(24.3-32.2)$ & 28.2 & $(24.6-32.3)$ & 26.5 & $(23.4-30.6)$ & 0.089 \\
\hline Male, $\mathrm{n}$ & 276 & $66.7 \%$ & 260 & $66.8 \%$ & 16 & $64.0 \%$ & 0.57 \\
\hline
\end{tabular}




\begin{tabular}{|c|c|c|c|c|c|c|c|}
\hline & All $(\mathrm{n}=414)$ & All $(n=414)$ & $\begin{array}{l}\text { Non-Stroke } \\
\text { Patients } \\
(\mathrm{n}=388)\end{array}$ & $\begin{array}{l}\text { Non-Stroke } \\
\text { Patients } \\
(\mathrm{n}=388)\end{array}$ & $\begin{array}{l}\text { Stroke } \\
(\mathrm{n}=26)\end{array}$ & $\begin{array}{l}\text { Stroke } \\
(\mathrm{n}=26)\end{array}$ & P-value \\
\hline $\begin{array}{l}\text { Deceased, } \\
\mathrm{n}\end{array}$ & 238 & $57.8 \%$ & 223 & $57.3 \%$ & 15 & $60.0 \%$ & 0.99 \\
\hline $\begin{array}{l}\text { Prior } \\
\text { CVA, n }\end{array}$ & 36 & $10.9 \%$ & 33 & $10.6 \%$ & 3 & $15.8 \%$ & 0.54 \\
\hline HTN, n & 208 & $62.7 \%$ & 194 & $62.2 \%$ & 14 & $70.0 \%$ & 0.48 \\
\hline HLD, n & 158 & $47.4 \%$ & 145 & $46.3 \%$ & 13 & $65.0 \%$ & 0.11 \\
\hline $\mathrm{DM}, \mathrm{n}$ & 108 & $32.4 \%$ & 104 & $33.1 \%$ & 4 & $21.1 \%$ & 0.22 \\
\hline $\begin{array}{l}\text { Lactic } \\
\text { Acid > } 10 \\
\mathrm{mmol} / \mathrm{L}, \mathrm{n}\end{array}$ & 71 & $17.8 \%$ & 69 & $18.4 \%$ & 2 & $8.0 \%$ & 0.16 \\
\hline $\mathrm{CPR}, \mathrm{n}$ & 95 & $23.1 \%$ & 91 & $23.6 \%$ & 4 & $16.0 \%$ & 0.33 \\
\hline $\mathrm{IABP}, \mathrm{n}$ & 93 & $24.7 \%$ & 90 & $25.4 \%$ & 3 & $13.0 \%$ & 0.15 \\
\hline Impella, n & 42 & $11.2 \%$ & 39 & $11.1 \%$ & 3 & $12.5 \%$ & 0.83 \\
\hline $\begin{array}{l}\text { Cardiogenic } \\
\text { Shock } \\
\text { Etiology }\end{array}$ & & & & & & & 0.96 \\
\hline PCS, n & 135 & $32.6 \%$ & 126 & $32.5 \%$ & 9 & $34.6 \%$ & 0.82 \\
\hline Graft, n & 54 & $13.0 \%$ & 52 & $13.4 \%$ & 2 & $7.6 \%$ & 0.40 \\
\hline AMI, $\mathrm{n}$ & 95 & $22.9 \%$ & 88 & $22.7 \%$ & 7 & $26.9 \%$ & 0.62 \\
\hline ADHF, n & 45 & $10.9 \%$ & 41 & $10.6 \%$ & 4 & $15.4 \%$ & 0.45 \\
\hline Other, $\mathrm{n}$ & 52 & $12.6 \%$ & 48 & $12.4 \%$ & 4 & $15.4 \%$ & 0.66 \\
\hline
\end{tabular}

$\mathrm{ADHF}=$ Acute Decompensated Heart Failure; AMI = Acute Myocardial Injury; BMI = Body Mass Index; $\mathrm{CPR}=$ Cardiopulmonary Resuscitation within 24 hours prior to ECMO cannulation; CVA = Cerebrovascular Accident; DM = Diabetes; Graft = Primary Graft Dysfunction; HLD = Hyperlipidemia; HTN = Hypertension; IABP = intra-aortic ballon pump; PCS = Postcardiotomy Shock; PCS includes those patients with inability to wean from cardiopulmonary bypass secondary to left, right or biventricular failure.

Supplementary Table S2: Stroke Incidence by Cannulation Date

Cannulation Site

\begin{tabular}{llllll}
\hline & Central & Axillary & Femoral & Total & p-value \\
Cohort 1 & $48(23 \%)$ & $22(11 \%)$ & $137(66 \%)$ & 207 & 0.001 \\
Cohort 2 & $29(14 \%)$ & $9(4 \%)$ & $169(82 \%)$ & 207 & \\
\hline
\end{tabular}

Stroke Incidence

\begin{tabular}{llllll}
\hline & Central & Axillary & Femoral & Total & p-value \\
Cohort 1 & $0(0 \%)$ & $1(4.5 \%)$ & $8(5.8 \%)$ & $9(4.3 \%)$ & 0.26 \\
Cohort 2 & $4(13.8 \%)$ & $1(11.1 \%)$ & $11(6.5 \%)$ & $16(7.7 \%)$ & \\
\hline
\end{tabular}

The study cohort was divided into two subgroups, "Cohort 1" and "Cohort 2". Cohort 1 includes the first 207 patients in our cohort who received ECMO, and Cohort 2 includes the second 207 patients of our study cohort who received ECMO. 


\section{References}

1. Gerke AK, Tang F, Cavanaugh JE, Doerschug KC, Polgreen PM. Increased trend in extracorporeal membrane oxygenation use by adults in the United States since 2007. BMC Res Notes. 2015;8:686.

2. Sauer CM, Yuh DD, Bonde P. Extracorporeal membrane oxygenation use has increased by $433 \%$ in adults in the United States from 2006 to 2011.Asaio j. 2015;61(1):31-36.

3. McCarthy FH, McDermott KM, Kini V, Gutsche JT, Wald JW, Xie D, et al. Trends in U.S. Extracorporeal Membrane Oxygenation Use and Outcomes: 2002-2012. Semin Thorac Cardiovasc Surg. 2015;27(2):81-88.

4. Shah M, Patnaik S, Patel B, Ram P, Garg L, Agarwal M, et al. Trends in mechanical circulatory support use and hospital mortality among patients with acute myocardial infarction and non-infarction related cardiogenic shock in the United States. Clin Res Cardiol.2018;107(4):287-303.

5. El Sibai R, Bachir R, El Sayed M. ECMO use and mortality in adult patients with cardiogenic shock: a retrospective observational study in U.S. hospitals. BMC Emerg Med. 2018;18(1):20.

6. Keebler ME, Haddad EV, Choi CW, McGrane S, Zalawadiya S, Schlendorf KH, et al. Venoarterial Extracorporeal Membrane Oxygenation in Cardiogenic Shock. JACC: Heart Failure. 2018;6(6):503-516.

7. Le Guennec L, Cholet C, Huang F, Schmidt M, Brechot N, Hekimian G, et al. Ischemic and hemorrhagic brain injury during venoarterial-extracorporeal membrane oxygenation. Ann Intensive Care. 2018;8(1):129.

8. Cheng R, Hachamovitch R, Kittleson M, Patel J, Arabia F, Moriguchi J, et al. Complications of extracorporeal membrane oxygenation for treatment of cardiogenic shock and cardiac arrest: a meta-analysis of 1,866 adult patients. Ann Thorac Surg. 2014;97(2):610-616.

9. Omar HR, Mirsaeidi M, Shumac J, Enten G, Mangar D, Camporesi EM. Incidence and predictors of ischemic cerebrovascular stroke among patients on extracorporeal membrane oxygenation support. J Crit Care. 2016;32:48-51.

10. Truby L, Mundy L, Kalesan B, Kirtane A, Colombo PC, Takeda K, et al. Contemporary Outcomes of Venoarterial Extracorporeal Membrane Oxygenation for Refractory Cardiogenic Shock at a Large Tertiary Care Center. ASAIO J. 2015;61(4):403-409.

11. Sacco RL, Kasner SE, Broderick JP, Caplan LR, Connors JJ, Culebras A, et al. An updated definition of stroke for the 21st century: a statement for healthcare professionals from the American Heart Association/American Stroke Association. Stroke.2013;44(7):2064-2089.

12. Mateen FJ, Muralidharan R, Shinohara RT, Parisi JE, Schears GJ, Wijdicks EFM. Neurological Injury in Adults Treated With Extracorporeal Membrane Oxygenation. Archives of Neurology.2011;68(12):1543-1549.

13. Kazmi SO, Sivakumar S, Karakitsos D, Alharthy A, Lazaridis C. Cerebral Pathophysiology in Extracorporeal Membrane Oxygenation: Pitfalls in Daily Clinical Management. Crit Care Res Pract.2018;2018:3237810.

14. Lorusso R, Barili F, Mauro MD, Gelsomino S, Parise O, Rycus PT, et al. In-Hospital Neurologic Complications in Adult Patients Undergoing Venoarterial Extracorporeal Membrane Oxygenation: Results From the Extracorporeal Membrane Support Organization Registry. Crit Care Med. 2016;44(10):e964-972.

15. Saeed O, Jakobleff WA, Forest SJ, Chinnadurai T, Mellas N, Rangasamy S, et al. Hemolysis and Nonhemorrhagic Stroke During Venoarterial Extracorporeal Membrane Oxygenation. Ann Thorac Surg.2019;108(3):756-763.

16. Mehta A, Ibsen LM. Neurologic complications and neurodevelopmental outcome with extracorporeal life support. World J Crit Care Med.2013;2(4):40-47. 
17. Werho DK, Pasquali SK, Yu S, Donohue J, Annich GM, Thiagarajan RR, et al. Epidemiology of Stroke in Pediatric Cardiac Surgical Patients Supported With Extracorporeal Membrane Oxygenation. Ann Thorac Surg. 2015;100(5):1751-1757.

18. Rollins MD, Hubbard A, Zabrocki L, Barnhart DC, Bratton SL. Extracorporeal membrane oxygenation cannulation trends for pediatric respiratory failure and central nervous system injury. J Pediatr Surg. 2012;47(1):68-75.

19. Pinto VL, Pruthi S, Westrick AC, Shannon CN, Bridges BC, Le TM. Brain Magnetic Resonance Imaging Findings in Pediatric Patients Post Extracorporeal Membrane Oxygenation. Asaio j. 2017;63(6):810-814.

20. Di Gennaro J, Farris R, McMullan D. 687: Risk of Stroke by Location of Arterial Cannulation and Age in Veno-Arterial ECMO. Critical Care Medicine. 2013;41(12).

21. Bulas D, Glass P. Neonatal ECMO: neuroimaging and neurodevelopmental outcome. Semin Perinatol. 2005;29(1):58-65. 